\title{
Communicating uncertainty: A step in the right direction?
}

Jonathan Marron ${ }^{1}$

${ }^{1}$ Dana-Farber/Boston Children's Cancer and Blood Disorders Center

November 30, 2020

\section{Hosted file}

Prognostic disclosure highlight for PBC Marron 11-28-20.pdf available at https://authorea. com/users/379809/articles/496036-communicating-uncertainty-a-step-in-the-right-direction 